\title{
REFLECTION OF LEAN LEADERSHIP BEHAVIORS IN ENHANCING THE STRATEGIC BALANCE OF BUSINESS ORGANIZATIONS
}

\author{
*Assistant Prof . Hussein Waleed Hussein, **Prof. Dr. Ghani Dahham Tanai Al-Zubaydi \\ *Ministry of Higher Education and Scientific Research \\ **College of Administration and Economics / University of Baghdad
}

DOI: $10.37648 /$ ijrssh.v10i02.041

Received: 15 $5^{\text {th }}$ April, 2020; Accepted: 05 ${ }^{\text {th }}$ May, 2020; Published: $15^{\text {th }}$ May, 2020

\begin{abstract}
The main purpose of this research is to identify the importance of the role played by lean leadership behaviors in enhancing the strategic balance of business organizations, within the framework of the contemporary dynamic environment that is characterized by a high degree of volatility and instability, which requires a high flexibility in dealing with it in order to maintain the special competitive position The organization for the longest possible period, and a problem has pointed to the low degree of awareness among the researched organizations of the importance of employing the behavior of their lean leaders in enhancing their strategic balance, so the importance of research emerges in providing a set of treatments for this problem, and in order to achieve a goal The research has adopted the descriptive analytical approach in its applied aspect, as the questionnaire was used to collect data, which was prepared based on a number of ready-made measures. As for the research sample, it was damaged by senior leaders in (24) Iraqi private college, as the sample size reached (227) individuals. The researcher adopted the ready-made statistical program (SPSS-V21) in entering and processing data, which produced a number of results that confirmed the existence of correlation and impact relations between the researched variables, and then the two main hypotheses from which the research was launched were accepted. The field of lean leadership behaviors and trying to transfer their ideas to Iraqi organizations, especially in the field of strategic balance.
\end{abstract}

Key words: lean leadership, strategic balance, business organizations, environment.

\section{INTRODUCTION}

Lean leadership behaviors are one of the main drivers adopted by business organizations in contemporary times, to deal with the successive developments that take place in their internal and external environments, in order to maintain the organization's ability to maintain its competitive advantage, market position and sustainability for the longest possible period, and perhaps the strategic balance represents one of the goals 
The main that must be achieved and to generate a set of sub-goals that emerge from it, and from this emerged the main idea of the research in identifying the importance of the role through which lean leadership behaviors affect the strategic balance of organizations. In order to achieve this idea, the research was divided into four topics, the first focused on the methodological pillars of the research, while the second topic focused on the theoretical philosophical implications of the researched variables, and the third topic came to present the most prominent results of the applied side, and finally the fourth topic presented the most important conclusions and recommendations that came out search.

\section{THE FIRST TOPIC: THE METHODOLOGICAL PILLARS OF THE RESEARCH}

\section{First: research problem}

The administration has witnessed developments in the nature of its variables through the historical stages of its development, and among the topics of great importance in the field of business administration are (lean leadership, strategic balance), which need more knowledge and theory discussion, and practical and scientific analysis to contribute to completing the journey of intellectual efforts Previous, and then diagnose the defect in the work environment with successive renewals that have not yet been satisfied to determine the nature of the relationship between them. The researcher was able to formulate his research problem, after conducting many interviews with the leaders in the researched organizations, and the field coexistence that lasted four months, as it became clear to him that these departments suffer from a clear decline in the perception of research variables and the extent of their importance, despite the application of some of these Variants before it, and use it to perform many different operations. Accordingly, the research problem can be summarized by the absence of awareness and knowledge awareness among the leaders of the faculties researched about the importance of employing lean leadership behaviors in the strategic balance, and in order to enhance the contribution of this research to address or reduce the effects of this problem, a set of questions arising from this problem have been formulated as follows:
1. What is the level of application of the sample organizations to lean driving behavior?

2. What is the level of organizations applying the research sample to strategic balance?

3. Is there sufficient awareness among the administrative leaders in the research organizations of the nature of the interrelationship between lean leadership and strategic balance?

4. Is there sufficient awareness among the administrative leaders in the research organizations of the impact of lean leadership and its contribution to strategic balance?

\section{Second: The importance of research}

The importance of scientific research emerges in the light of the researched variables that seek to study them, which constitute one of the contemporary administrative concepts, which reflect the orientations of successful organizations and capable of sustaining their operations, within the framework of their dynamic environment, in order to contribute to enhancing knowledge and then bridge the shortage experienced by the Iraqi library in this The field, drawing on many modern references, especially foreign ones, that made up the largest proportion of research sources. The field is also important for research within the framework of the research sample, which is represented by members of sample boards of Iraqi private colleges, who represent the bodies that manage the march of private education within the country, measuring the relationships of interconnection and influence between the variables discussed, with their specifics specified in the hypothesis of the research, to present a new special model In the Iraqi environment, to propose proposing a set of mechanisms, which represent solutions to the problems facing the researched organizations, and to the extent related to the variables discussed.

\section{Third: Research objectives}

The main objectives of this research can be summarized as follows:

1. Discussing a set of philosophical pillars for a number of previous studies, to provide a modest theory addition to lean leadership and its most important behaviors in contemporary organizations.

2. See the theoretical foundations and concepts of strategic balance and discuss the terminology 
equivalent to it, in order to deepen knowledge of the importance of its components to contemporary organizations.

3. Knowing the degree of interest in lean leadership behaviors in the researched organizations, through diagnosing their reality and their relative importance.

4. Identify the most prominent areas of strategic balance in the researched organizations, by diagnosing their reality and their relative importance.

5. Diagnosing the degree to which lean leadership behaviors contribute to the strategic balance of the researched organizations in light of the interrelationships and impacts.

\section{Fourth: The hypothesis of the research}

The research outline summarizes its main idea, by clarifying the nature of the correlation and influence relations between the variables that the researcher is trying to study, and what is the nature of the paths these relationships take. As for the expected result of it, the contribution of the explanatory variable to the response variable can be increased, and through Figure (1) this can be clarified :

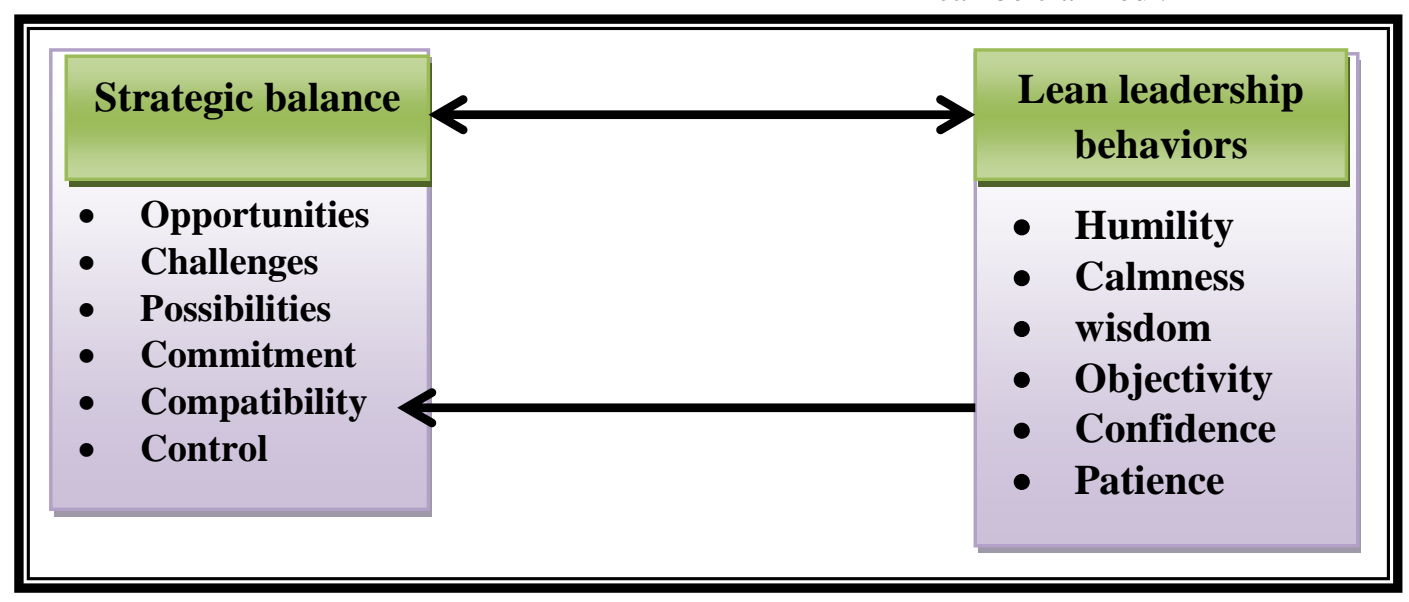

Figure (1) hypothetical research scheme

Fifth: research hypotheses

This research includes two main hypotheses:

1. The first main hypothesis: It states that "the adoption of lean leadership behaviors plays a significant role statistically in the strategic balance of the researched organizations." It clarifies the interrelationships between them.

2. The second main hypothesis: This hypothesis stipulates the following: " lean leadership behaviors contribute statistically to the strategic balance of the researched organizations", and it explains the influence of relations between them.

\section{Sixth: Research tools}

The researcher adopted the descriptive analytical approach in preparing the research, and the questionnaire was used as a main tool for collecting data, as the researcher designed a questionnaire, using international standards and using them in a way that is compatible with the research variables, after it was adapted to suit his goals as the researchers' ideas were used (Andersson , 2014) \& (Thureeson \& Ostman, 2017) In preparing lean leadership paragraphs. As for the strategic balance paragraphs, they were prepared based on the researchers' ideas (Alshebli , 2016) \& (Moses \&Ekwutosi, 2018). The (Likert quintet) runway was used in its design. The questionnaire was subjected to apparent honesty tests (honesty of the arbitrators), to ensure its ability to measure the variables that the researcher is trying to study, and the researcher presented the questionnaire to a number of arbitrators in the fields of (business administration, measurement and evaluation, and statistics) numbering (22), and within the framework of Their observations and opinions were not deleted any of the paragraphs of the questionnaire, and thus settled on (80) paragraphs, but most of its paragraphs were rewritten and many were abbreviated, and after conducting the statistical analysis to identify the percentage of agreement achieved by the questionnaire reached $(93 \%)$, which is an excellent percentage and 
confirms Its ability, to assist the researcher to achieve the goals that he seeks Guardian in this search. As for stability, it is one of the measures that is used to identify the reliability of the questionnaire. There are two types of stability: the internal stability that reflects the degree of compatibility between the questionnaire paragraphs with each other, and the Cronbach, s alpha factor has been used in measuring it using the answers of the arbitrators, and that the ratio of the stability factor The value of (0.67), and the stability results of the subdimensions and the main variables of the questionnaire ranged between (0.85-0.93) and they are all higher than (0.67), and the stability ratio of the questionnaire as a whole (0.89), and this result came in line with the sincerity value The content reached (0.94), so it is characterized by stability and internal consistency between poverty Its different dimensions and subdimensions. As for external stability, the researcher distributed the questionnaire to a sample of (50) individuals in the colleges (Israa, Al-Rafidain, and AlNisour), and after (20) days, it was redistributed again, and upon analyzing the data, the correlation relationship between them was $(0.79 * *)$ which is A strong positive relationship at the level of significance (0.01), and it indicates in a significant way that the questionnaire, the results are the same if they are distributed, on the same sample at different times.

The researcher relied on three statistical programs that are ready to deal with the data of his research, which are (SPSS. V21, AMOS \& Excel). As for the most important tools that were used in conducting statistical operations, for the first research from the applied side are:

1. The percentage of the agreement: One of the measures of central tendency that are used to identify the percentage of agreement among the respondents about the presence of research variables within the researched organization, and compare it with the standard value of the agreement of $66.7 \%$.

2. Arithmetic mean: It is considered one of the most important measures of central tendency, and it is used to identify the level of presence of the researched variable in the field of application. It is calculated by dividing the algebraic sum of degrees by their number, which is compared to the value of the hypothetical arithmetic mean of (3).

3. Standard deviation: It is one of the most important scattering scales that indicates the degree of harmony between the responses of the sample members toward the researched variables and their resolution questionnaires. It is calculated from finding the square root of the mean square of the deviations of degrees from their mean.

4. Variation coefficient: a measure of the relative dispersion that can be used to find out the level of dispersion of the answers of the research sample from its mean, as the lower its value, the less dispersion will be calculated by dividing the value of the standard deviation by the value of the mean.

5. Correlation coefficient: It is used to identify the strength of the linear relationship and the direction between the two variables, in order for the researcher to determine the existence of the relationship or its lack of statistically, and then test the hypotheses that state the existence of the relationship between the variables discussed.

6. Simple linear regression coefficient: A case of multiple regression is used when the number of explanatory variables is equal to one to identify its effect on the response variable, that is, it is used to test the influence hypotheses among the searched variables.

\section{Seventh: The research community and its sample}

The current research community was represented by the private colleges recognized by the Iraqi Ministry of Higher Education and Scientific Research for the academic year 2019/2020, as the number of private university colleges reached (48) colleges, while the number of private universities reached (15) universities, comprising (78) colleges, Therefore, the total number of private colleges representing the current research community is (126) colleges (Department of Private Education / Iraqi Ministry of Higher Education and Scientific Research), (24) colleges were chosen, which are (Al-Rafidain University College, College of University Heritage, Mansour University College, AlMamoun College University, College of Education, University College, Shatt Al-Arab University, Baghdad College of Highness Economic University, College of Islamic Sciences / Islamic University, College of Law and Political Science / Islamic University, College of Arts / Imam Jaafar Al-Sadiq University (AS), College of Information Technology / Imam Jaafar Al-Sadiq University (AS), College of Law / Imam Jaafar Al-Sadiq

\section{INTERNATIONAL JOURNAL OF RESEARCH IN SOCIAL SCIENCES AND HUMANITIES}


University (AS) ), Imam Balad College, Future University College, Isra University College, Mustafa University College, Elite University College, Elite University College, College Eagles University, College of Engineering / Uruk University, College of Engineering / Islamic University, College of Assyria University, College of Administrative and Financial Sciences / Al-Imam Jaafar Al-Sadiq University (AS), Faculty of Administration and Economics / Uruk University.).

As for the research sample, the intentional (intended) sample method was used in determining the sample to which the questionnaire will be distributed, as members of the National College Council were chosen as a sample for research in the research colleges referred to above, and the questionnaires were distributed by (227) questionnaires, which were retrieved completely, And no questionnaire was neglected, as they all meet the requirements of statistical analysis. Among the most prominent characteristics of the sample, the percentage of males in the research sample formed $(85 \%)$, while the percentage of females (15\%). There are no members of the study sample whose ages are less than (25 years), while (52) of them, i.e. (23\%) of the total sample population, ranged between (26-40 years), and (86) of them At a rate of $(38 \%)$ of the total research sample, their ages range between (41-55 years), and the largest percentage that reached $(39 \%)$ who are over the age of 56 years and over, as they reached (89) individuals. Also, (174) individuals from the research sample, that is (77\%) of the total sample are holders of (Ph.D. degree), and this result reflects, in clear terms, that the researched organizations rely on $\mathrm{PhD}$ holders to assume administrative positions in them and exercise leadership functions. , While (53) of them lost, i.e. (23\%) of the sample they had (master's degree). And that (24) of the research sample, i.e. (11\%) of the total sample, which is the lowest percentage they have a service (less than five years), and perhaps the reason for that is due to its recent development of some organizations that were chosen as a field of application, while (43) of them, that is (19\%) of the total sample surveyed have a service of (5-10 years), and that (67) of the surveyed sample, meaning that $(29 \%)$ have a service that ranged between (11-20 years) Finally, (93) of the respondents have a service of more than (21 years), which is the largest percentage that reached $(41 \%)$. Also, (24) of the research sample, that is
$(11 \%)$ of the total research sample occupied the position of (Dean), while (37) of them, i.e. (16\%\%) of the total sample, occupied the position of (Associate Dean) ) Whether for administrative, scientific or student affairs, as for the largest percentage of the research sample, they occupied the position of (department head), as their number reached (166), which means $(73 \%)$ of the total research sample. With regard to the scientific title, the largest percentage of the research sample is from the title of (Assistant Professor), as they numbered (92), which means $(41 \%)$ of the total research sample, and in second place came the title of (Professor) with a percentage (28\%) As they numbered (63), these numbers give a clear indication of the organizations 'reliance on the application of advanced scientific titles, when assigning those occupying leadership positions within them, as their combined percentage (69\%) of the research sample. As for the holders of the title (teacher), they came third $(22 \%)$ and numbered (51). Finally, the title (assistant teacher) came with (9\%) and number (21).

\section{THE SECOND TOPIC: THEORETICAL SIDE}

This topic was devoted to the purpose of identifying the most important foundations and intellectual premises addressed by researchers in studying the variables discussed, in order to draw on them by the researchers in formulating theoretical research paragraphs as follows:

\section{First: the concept of lean leadership}

The concept of lean leadership is a contemporary concept in the field of business administration, as many applied and intellectual studies have emerged that confirm the importance of this term, and the maturity it has reached in recent times. As lean leadership has been defined by several definitions, from a behavioral point of view it is defined as: "Behaviors that contribute to creating value for the organization by reducing negative attitudes in work such as abuse of procedures, hostile behavior, lack of sharing of ideas, weak relationships and lack of cooperation" (Emiliani, 1998: 617), and by focusing on the investment aspect, it was defined as: "Leadership with sufficient capabilities, to participate in exploratory activities and investment activities simultaneously, in order to achieve a balance between the contradictions that they may encounter in work, compared to the present and the future" (Mohabir, 2008: 
8), as was done Wara by the researcher (Nicholas, 2010:

1) in the tariff for the leadership elegans is essential that is characterized by three qualities of a head of speed, flexibility and continuous flow. The researcher believes that these definitions emphasized the importance of lean leadership in supporting and rationalizing the organization's investment decisions through its own behaviors. Through table (1), some definitions of lean driving can be clarified:

Table (1) the definitions of lean leadership according to the directions of a number of researchers and writers

\begin{tabular}{|c|c|c|}
\hline $\bar{T}$ & Researcher and Year & the definition \\
\hline 1 & $\begin{array}{l}\text { Teich \& Faddoul , } \\
2013: 2\end{array}$ & $\begin{array}{l}\text { Systematic approach to ensure the sustainable implementation of flexible } \\
\text { production systems, and continuous improvement of the organization's } \\
\text { operations. }\end{array}$ \\
\hline 2 & $\begin{array}{l}\text { Schwagerman } \\
\text { Ulmer , } 2013: 6\end{array}$ & $\begin{array}{l}\text { Leadership that supports learning processes, by encouraging dialogue and direct } \\
\text { interaction, between all human resources operating within the organization. }\end{array}$ \\
\hline 3 & $\begin{array}{l}\text { Amer \& Shaw , } 2015 \text { : } \\
273\end{array}$ & $\begin{array}{l}\text { Leaders who have a full awareness of the organization's vision, to apply agility in } \\
\text { carrying out their activities and tasks, and to establish a mechanism to deliver it } \\
\text { to its human resources. }\end{array}$ \\
\hline 4 & Mulders , 2016, 19 & $\begin{array}{l}\text { Systematic system to achieve the desires of customers, workers and the leader, } \\
\text { by focusing on continuous improvement, to ensure successful implementation in } \\
\text { the long term. }\end{array}$ \\
\hline 5 & $\begin{array}{l}\text { Fernando \& Klaus } \\
\text { 2016:235 }\end{array}$ & $\begin{array}{l}\text { The contemporary approach to human resource leadership, focusing on } \\
\text { technical and psychological skills and expertise, to motivate them to make the } \\
\text { utmost effort to achieve the goals of the organization. }\end{array}$ \\
\hline 6 & $\begin{array}{l}\text { Zulkiffli \& Latiffi , } \\
2019: 4\end{array}$ & $\begin{array}{l}\text { Leadership with the capacity to identify critical success factors, and manage } \\
\text { them in a manner that ensures the sustainability of the organization's successes. }\end{array}$ \\
\hline
\end{tabular}

Source: Preparing the two researchers based on the ideas of the researchers referred to above.

Lean leadership can be defined for the purposes of the current research as: (It represents contemporary leadership trends that depend on a set of behaviors, most notably "humility, calmness, trust, objectivity, patience, and wisdom", in order to invest the resources available to the organization in the best possible way, and direct it towards goals and strategy That you seek, in a way that helps it excel in the sector in which it operates). It was emphasized that the importance of lean leadership in major organizations is clearer than it is in small organizations, given that these organizations have an executive director who carries out all leadership tasks, and in multiple regions or countries (Marksbeffy \& Hughes, 2011: 3). The study that he conducted (Begam el at, 2013: 15) confirmed that lean leadership is one of the foundations for the success of organizations at the international level, especially we live in the era of globalization and great progress in the field of technology, due to its importance in achieving coordination and compatibility between all components of the organization and in countries Various, as well as being important in fostering uncle Yeh learning a way that develops the skills and capabilities of human resources, in order to fit the culture of the organization by promoting and stimulating the spirit of cooperation and interaction between them, and regardless of their career site (Schwagerman \& Ulmer, 2013: 5). Dimensions (humility, calmness, wisdom, patience, objectivity, and confidence) will be adopted for the purpose of studying lean leadership in the applied aspect of research as follows:

1. Modesty Behavior: Modesty is one of the ethical behaviors of lean leadership, which emphasizes how to think in an acceptable way by all parties dealing with the organization about the implementation of its operations (Schipper \& Swets, 2010: 45).

2. Calm behavior: In this behavior, lean leadership deals with the multiple problems that it faces, due to the large number of work and the variations of the 
environment quietly branching out, when making crucial decisions regarding the future of the organization, in other words the behaviors that help lean leadership to think deeply and carefully, and focus on the essence Avoiding lateral driving to reach the best solutions, and then ensuring that operations are running in the right direction (Schwagerman \& Ulmer, 2013: 5).

3. Behavioral of Wisdom: This behavior emphasizes the ability of lean leadership to strike a balance between the scarce resources available to the organization, and the multiple activities and tasks it carries out, especially in the area of the strategy it seeks (Halling \& Renstrom, 2015: 1509).

4. Objectivity of Behavior: This behavior emphasizes lean leadership in dealing rationally with its human resources, regardless of many personal characteristics, and secondary factors that could influence them (Mulders, 2016: 22).

5. Confidence behavior: That is, the lean leadership has sufficient confidence in their capabilities and capabilities, to carry out their activities and tasks, in light of the difficult circumstances in which they work, as well as their ability to enhance confidence in the human resources that they deal with, about their most important capabilities, capabilities and competence to achieve success. Regulatory (Thuresson \& Ostman, 2017: 30).

6. Patience behavior: This behavior relates to the ability of the lean leadership to accept the delay in achieving the goals, and to achieve the privileges and successes that you seek, that is, the lean leader has patience in investing enthusiasm, energy, skills and knowledge available to him and his human resources, to achieve cohesion and avoid laziness and inactivity in the long term More than in the short term (Puvanasvaran el at, 2016: 456).

\section{Second: The concept of strategic balance}

Strategic Balance is one of the widespread contemporary strategic concepts, which focus on studying the environment that operates within its internal and external organizational boundaries, and how to achieve a balance between them, so this concept has gone out of being theoretical and philosophical ideas to practical and applied practice, because of its importance in helping Business organizations achieve their goals and strategies. The strategic balance was referred to as "the means used by the organization to balance the different competitive strategies (differentiation, cost leadership, and concentration) in providing its products to its customers to maintain its position in the market" (Iman \& Hartono, 2007: 255), and according to the systems approach it has It was defined as "the dynamic relationship that links all the forces affecting the organization, in an integrated system that supports each other, in order to ensure the dissemination of knowledge and information available to it within the limits of its internal and external environment" (Kearns \& Sabherwal, 2007: 130), as the researcher sees from During the previous definition, strategic balance represented Alone the main engines for the dissemination of knowledge within the organization. Through table (2), it is possible to clarify some definitions of strategic balance that the researcher is able to define after reviewing the intellectual and research efforts of researchers and previous interested persons:

Table (2) Definitions of strategic balance based on the ideas of some researchers

\begin{tabular}{|c||l|l||}
\hline \hline & $\begin{array}{l}\text { Researcher and } \\
\text { Year }\end{array}$ & the definition \\
\hline \hline 1 & Barth, 2003: 134 & $\begin{array}{l}\text { The process by which the organization seeks to balance its strengths and weaknesses } \\
\text { in the internal environment, with external opportunities and threats that hinder its } \\
\text { continued operation. }\end{array}$ \\
\hline \hline 2 & $\begin{array}{l}\text { Nkhwangwa , 2014 } \\
: 147\end{array}$ & $\begin{array}{l}\text { A mechanism adopted by the organization to achieve a balance between the sub- } \\
\text { strategies and the president, which it seeks to achieve in order to raise the level of } \\
\text { investment for the resources available to it. }\end{array}$ \\
\hline \hline 3 & $\begin{array}{l}\text { Majukwa , 2016 : } \\
3\end{array}$ & $\begin{array}{l}\text { One of the tools approved in formulating the strategy approved by the organization, } \\
\text { to achieve a balance between market opportunities and the capabilities available to } \\
\text { them. }\end{array}$ \\
\hline \hline
\end{tabular}




\begin{tabular}{|l||l|l|l|}
\hline \hline 4 & $\begin{array}{l}\text { Rahman } \\
\text { Rahman, 2019:45 }\end{array}$ & $\begin{array}{l}\text { One of the contemporary trends to meet the needs of customers in the external } \\
\text { environment through the resources and capabilities that the organization possesses } \\
\text { in its internal environment. }\end{array}$ \\
\hline
\end{tabular}

Source: Preparing the two researchers based on the ideas of the researchers referred to above.

The researchers can define the strategic balance for the purposes of the current research and based on its own dimensions as: "The instrument that the organization adopts to balance its internal environment represented by (capabilities, compatibility, commitment, and control), with its external environment represented by (opportunities and threats) in order to ensure its survival and continuity At work, by activating the implementation of its strategy to maintain its market share. " Organizations can use the strategic balance to achieve a balance between revenues and expenses related to them, according to international standards through a balance between the financial statements of the organization, and the bodies responsible for preparing them (Osma \& Pope, 2011: 2), and its importance in identifying critical success factors that Determine the fate of the organization in its future, and the most important elements adopted by the top management in upgrading performance levels to all organizational levels (Van, 2011: 68). Strategic balance also plays an important role in comparing the organization's internal capabilities, and the available capacities in the market in a manner that identifies the most important areas of economies of scale, or economies of scale to develop appropriate strategies for their exploitation (Destri el at, 2012: 26), and based on the findings of a study ( (Jhajharia \& Kaur, 2015: 53-54) It contributes morally to enhancing the role that human resources play in implementing the overall organization strategy, by providing them with all the information on the external environment, and in high quality to solidify all the decisions that they make. The researcher will depend on measuring Strategic balance in The applied aspect of this research has six components, two representing the external balance, which are (opportunities and challenges) for the external environment, and four representing the internal balance, which are (capabilities, compatibility, commitment, oversight), and the following are clarifications of their concepts:

1. Opportunities: Opportunities express external situations and locations that are positively compatible with the direction of the organization, and enhance its ability to adapt to developments facing it at work (Rudelius, 2007: 33).

2. Challenges: It is the set of events and variables that stand in the way of the organization, preventing it from carrying out its work and achieving its best performance, which results in negative effects on its competitive advantage, and contributes negatively to reducing the market share it has within its sector (Wheelen \& Hungerv, 2010: 224),

3. Capabilities: means the capabilities available to the organization that help it to carry out its tasks and functions, and in coordination with all parties related to its operations, and before identifying these capabilities it is necessary to indicate that the strengths that exercise a positive role in the work, and contribute strongly to strengthening the ability The organization to achieve its goals is represented by these capabilities, as well as points of weakness that indicate a state of shortage or poverty in these capabilities, compared to the organizations competing with the organization, and impede its ability to carry out its various operations (Nkhwangwa, 2014: 145).

4. Commitment: This dimension is directly related to the human resources working within the organization, which is one of the tools that it adopts in achieving the strategic balance, it represents the psychological phenomenon and the emotional state that the individual feels by enjoying work inside the organization, and the freedom to act at all organizational levels, which strengthens Their desire to serve and achieve its goals (Noordin el at, 2010: 2).

5. Compatibility: That is, the organization's ability to achieve compatibility between its human resources and the activities and tasks assigned to them, at the various organizational levels to ensure that its affairs are conducted in the best possible way, and this in turn will be reflected in building a strong culture within the organization, contributing to achieving the strategic balance between its internal levels and between the entities Externalities that you work

\section{INTERNATIONAL JOURNAL OF RESEARCH IN SOCIAL SCIENCES AND HUMANITIES}


with, to ensure that there is no regression or obsolescence in comparison between the two environments (Xu et al, 2006: 13).

6. Control : That is, the organization's ability to follow up on all the processes that are carried out within it to achieve its goals, which are the measurable and achievable results during a specific period of time, within the framework of the environment that operates within its borders, and which represents one of the main guides for the decision-making process that falls on the administration Olaya (Rotemberg \& Saloner, 2000: 697).

Third: The philosophical premise of the relationship between lean leadership and strategic balance

This paragraph focuses on diagnosing the nature of the relationship between lean leadership and its behaviors with strategic balance, to identify the foundations upon which the researcher relied in formulating research hypotheses. It is necessary for the lean leadership to balance the various goals pursued by the organization, and the competitive criteria that it will aim at such as reliability and competencies in the internal environment, with the opportunities and threats that it witnesses in the external environment, to achieve a strategic balance between them (Yukl \& Mahsud, 2010: 82), as well as The lean leadership is responsible for communicating the goals of the organization to its employees, and therefore it must strike a balance between its goals and the directions of human resources, because they are the body responsible for implementing them and this is the essence of the strategic balance internally (Marksbeffy \& Hughes, 2011: 6), as the study concluded. By (Ljungblom, 2012: 62) that equilibrium is one of the prerequisites to help lean leadership reduce behavior that is inappropriate for the organization. From the point of view of the researcher (Lopez-Fresno, 2012: 92-93), the most important factors affecting lean leadership were identified with a focus on the principles of total quality management with twelve work factors which are "senior management commitment, cooperative leadership, culture, complexity, strategic balance, conformity Strategy with operations, commitment of individuals, availability of resources, use of information technology, performance measures, specialized design, and digital implementation. "So it is clear that strategic balance represents one of the factors affecting the success of lean driving behaviors, and lean leadership skills contribute to achieving a balance between all The owners of pain The case that the organization deals with them in a way that ensures that there is no conflict between them (Marques, 2013: 168), as the study conducted by researchers (Begam el at, 2013: 20) confirmed that one of the forces supporting the lean leadership practices is the organized desire to achieve Strategic balance with the external environment, and continuously to adapt to the changes that take place in it, and therefore researchers (Shatrevich \& Gaile-Sarkane, 2015: 1) stressed that lean leadership is the tool that the organization adopts to achieve a balance between its culture and its internal strategy and the external environment.

\section{THE THIRD TOPIC: THE APPLIED SIDE}

In this topic, the reality of the researched variables and their relative importance will be diagnosed to identify the degree of their presence within the researched organizations, and then test the two main hypotheses that were included in the research, as in the following paragraphs:

First: Diagnosing the relative importance and reality of lean driving behavior

The variable of lean leadership was measured through six dimensions represented by its behaviors: "behavior of modesty, behavior of calm, behavior of wisdom, objectivity behavior, behavior of trust, and behavior of patience." Through table (3), the reality of the explanatory variable (lean leadership) and its subdimensions can be diagnosed. , By displaying its analysis results:

Table (3) Results of analyzing the reality and diagnosing lean leadership behaviors

\begin{tabular}{|l|l|l||l|l||l||}
\hline The dimension & $\begin{array}{l}\text { Agreement } \\
\text { rate }\end{array}$ & $\begin{array}{l}\text { Arithmetic } \\
\text { mean }\end{array}$ & $\begin{array}{l}\text { standard } \\
\text { deviation }\end{array}$ & $\begin{array}{l}\text { Coefficient of } \\
\text { variation }\end{array}$ & $\begin{array}{l}\text { The level of } \\
\text { importance }\end{array}$ \\
\hline \hline Confidence behavior & $\% 76$ & 4.06 & $\mathbf{0 . 6 3}$ & $\mathbf{0 . 1 5}$ & 1 \\
\hline
\end{tabular}




\begin{tabular}{||l||l||l|l|l||l||}
\hline Wisdom behavior & $\% 74.8$ & 4.01 & 0.66 & 0.17 & 2 \\
\hline Calm behavioral & $\% 74.4$ & 4.01 & 0.60 & 0.15 & 3 \\
\hline Behavioral patience & $\% 76.4$ & 3.97 & 0.63 & 0.16 & 4 \\
\hline Humility behavior & $\% 75.2$ & 3.96 & 0.59 & 0.15 & 5 \\
\hline Objective behavior lean & $\% 73$ & 3.95 & 0.66 & 0.17 & 6 \\
\hline $\begin{array}{l}\text { Aggregate } \\
\text { leadership behavior } \\
\text { variable }\end{array}$ & $\% 75$ & 3.99 & 0.63 & 0.16 & \\
\hline
\end{tabular}

Source: Prepared by the researchers, 2020.

To determine the percentage of the agreement for the total lean driving variable, reference can be made to Table (3), as its value reached (75\%), which is a good percentage from a statistical point of view and higher than the standard percentage of the agreement $(66.7 \%)$, and indicates with clear indication that most of the respondents confirm that the leaders In their organization, they have lean leadership behaviors that enable them to carry out the activities and tasks assigned to them, in a manner consistent with the directions of the parties that deal with them inside and outside the organization, as well as with the successive developments and developments taking place in their environment. The value of the arithmetic mean for the total lean driving variable came to confirm its presence at a high level within the researched organizations, as its value (3.99) was also higher than the value of the hypothetical mean of (3), and the value of the standard deviation was (0.63), which confirms and in its terms clear in terms of Statistically, the presence of high harmony among the respondents in the direction of the lean leadership variable paragraphs, and what confirms this result is the value of the difference coefficient of
0.16 , which reflects the lack of dispersion between the answers, and these results were consistent with the results related to the sub-dimensions of the lean leadership. As we note from the table above, behavior of confidence came first, as the value of its arithmetic mean reached (4.06), whereas behavior of wisdom ranked second with arithmetic mean (4.01) and agreement rate $(74.8 \%)$, and in third rank calm behavior came with arithmetic mean (4.01) But with an agreement rate $(74.4 \%)$, while the behavior of patience came in the fourth rank with a value of an arithmetic mean of (3.97).

Second: Diagnosing the relative importance and the reality of the strategic equilibrium variable

The strategic equilibrium variable was measured through six dimensions, two dimensions representing the external balance (opportunities, challenges), and four dimensions representing the internal balance, which are (capabilities, commitment, agreement, control), i.e. forming a total of six dimensions. Table (4) shows the most prominent results of diagnosing the reality of these dimensions and their relative importance in the researched organizations:

Table (4) Results of Reality Analysis and Diagnosis of Strategic Balance

\begin{tabular}{|c|c|c|c|c|c|}
\hline The dimension & $\begin{array}{l}\text { Agreement } \\
\text { rate }\end{array}$ & $\begin{array}{l}\text { Arithmetic } \\
\text { mean }\end{array}$ & $\begin{array}{l}\text { standard } \\
\text { deviation }\end{array}$ & $\begin{array}{l}\text { Coefficient } \\
\text { of variation }\end{array}$ & $\begin{array}{l}\text { The level of } \\
\text { importance }\end{array}$ \\
\hline Compatibility & \%80 & 4.01 & 0.60 & 0.15 & 1 \\
\hline Commitment & $\% 77$ & 4.00 & 0.65 & 0.16 & 2 \\
\hline Oversight & $\% 77$ & 3.99 & 0.63 & 0.16 & 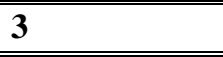 \\
\hline Possibilities & $\% 76$ & 3.97 & 0.63 & 0.16 & 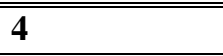 \\
\hline Opportunities & $\% 71$ & 3.94 & 0.65 & 0.17 & 5 \\
\hline Challenges & \%71 & 3.91 & 0.59 & 0.15 & 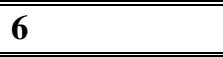 \\
\hline $\begin{array}{l}\text { Total strategic equilibrium } \\
\text { variable }\end{array}$ & $\% 75$ & 3.97 & 0.63 & 0.16 & \\
\hline
\end{tabular}


Source: Prepared by the researchers, 2020.

To determine the overall importance of the strategic balance variable, reference can be made to Table (4), as its agreement rate reached (75\%), which is a good percentage and higher than the standard percentage of the agreement, and confirms the interest of the researched organizations in achieving the strategic balance through monitoring and monitoring developments that occur in their external environment, Then making the required adjustments to confront them in their internal environment, as the value of the arithmetic mean for the total strategic equilibrium variable reached (3.97), which is also higher than the value of the hypothetical mean of (3) and confirms the interest of the researched organizations in achieving their strategic balance at a high level, and with a deviation Standard (0.63) and this result confirms that there is a high degree of consistency in statistical terms between the answers of the researched sample towards the paragraphs of the strategic balance, and the value of a different coefficient came to confirm the lack of dispersion between the answers, as its value (0.16). As it becomes clear from Table (4), that after compatibility, it came first with a value of the arithmetic mean that reached (4.01), while it came after committing to the second rank with an arithmetic value of (4), and after it came after monitoring the third rank with an arithmetic mean (3.99), and it occupied After the capabilities, the fourth rank came with an arithmetic mean (3.97), and after the opportunities, it came in the fifth rank, as the value of his arithmetic value reached (3.94), while he ranked last after the challenges with an arithmetic mean (3.91).

Third: Analysis and interpretation of the results of the interrelationships between lean leadership and strategic balance

In this paragraph, the researcher tries to test the first major hypothesis of the research, which we notice from table (5) the matrix of correlations between the two variables and their dimensions, which includes (49) correlations, as the horizontal level of the table shows the main dimensions of the strategic equilibrium variable (Y) included: " Opportunities, challenges, capabilities, commitment, compatibility and oversight. " At the vertical level, the main dimensions of lean leadership (X) include: "modesty behavior, calm behavior, wisdom behavior, objectivity behavior, trustworthiness behavior, and patience behavior." The following is an explanation of the most prominent of these results:

Table (5) Results of the interrelationships between lean leadership and strategic balance

\begin{tabular}{|c|c|c|c|c|c|c|c|c|c|c|}
\hline & & \multirow{2}{*}{$\begin{array}{l}\text { Opport } \\
\text { unities }\end{array}$} & \multirow{2}{*}{$\begin{array}{l}\text { Challen } \\
\text { ges }\end{array}$} & \multirow{2}{*}{$\begin{array}{l}\text { Possibil } \\
\text { ities }\end{array}$} & \multirow{2}{*}{$\begin{array}{l}\text { Commit } \\
\text { ment }\end{array}$} & \multirow{2}{*}{$\begin{array}{l}\text { Compati } \\
\text { bility }\end{array}$} & \multirow{2}{*}{ control } & \multirow{2}{*}{$\begin{array}{l}\text { Total } \\
\text { strategic } \\
\text { balance }\end{array}$} & \multicolumn{2}{|c|}{ Moral relationships } \\
\hline & & & & & & & & & $\begin{array}{l}\text { the } \\
\text { number }\end{array}$ & $\begin{array}{l}\text { Relative } \\
\text { importance }\end{array}$ \\
\hline \multicolumn{2}{|c|}{ Humility behavior } & $* * 0.570$ & $* * 0.720$ & $* * 0.703$ & $* * 0.751$ & $* * 0.723$ & $* * 0.738$ & $* * 0.779$ & 7 & $\% 100$ \\
\hline \multicolumn{2}{|c|}{ Calm behavioral } & $* * 0.723$ & $* * 0.807$ & $* * 0.753$ & $* * 0.740$ & $* * 0.673$ & $* * 0.718$ & $* * 0.791$ & 7 & $\% 100$ \\
\hline \multicolumn{2}{|c|}{ Wisdom behavior } & $* * 0.703$ & $* * 0.845$ & $* * 0.750$ & $* * 0.790$ & $* * 0.743$ & $* * 0.793$ & $* * 0.848$ & 7 & $\% 100$ \\
\hline \multicolumn{2}{|c|}{ Objective behavior } & $* * 0.597$ & $* * 0.804$ & $* * 0.733$ & $* * 0.814$ & ***0.713 & $* * 0.723$ & $+* * 0.799$ & $\overline{77}$ & $\% 100$ \\
\hline \multicolumn{2}{|c|}{ Confidence behavior } & $* * * 0.609$ & $* * 0.800$ & $* * 0.707$ & $* * 0.768$ & $* * 0.710$ & $* * 0.688$ & $* * 0.781$ & $\overline{7}$ & $\% 100$ \\
\hline \multicolumn{2}{|c|}{ Behavioral patience } & $* * 0.605$ & $* * 0.790$ & $* * 0.696$ & $* * 0.790$ & $* * 0.751$ & $* * 0.786$ & $* * 0.807$ & 7 & $\% 100$ \\
\hline \multicolumn{2}{|c|}{ Lean leadership } & $* * 0.722$ & $* * 0.900$ & $* * 0.814$ & $* * 0.888$ & $* * 0.816$ & $* * 0.849$ & $* * 0.911$ & 7 & $\% 100$ \\
\hline \multirow{2}{*}{$\begin{array}{l}\text { al } \\
\text { relationships }\end{array}$} & $\begin{array}{l}\text { the } \\
\text { numb } \\
\text { er }\end{array}$ & 7 & 7 & 7 & 7 & 7 & 7 & 7 & \multirow[t]{2}{*}{49} & \multirow[t]{2}{*}{$\% 100$} \\
\hline & $\begin{array}{l}\text { Relati } \\
\text { ve }\end{array}$ & $\% 100$ & $\% 100$ & $\% 100$ & $\% 100$ & $\% 100$ & $\% 100$ & $\% 100$ & & \\
\hline
\end{tabular}




\section{impor}

tance

* Correlation at the level of significance 0.05 .

** Correlation at the level of significance 0.01 .

Source: Prepared by the researchers, 2020.

By looking at the results mentioned in Table (5), it turns out that the lean leadership variable and its dimensions achieved (49) positive correlations with significant significance, out of (49) relationships with the strategic equilibrium variable and its dimensions, that is, what constitutes $(100 \%)$ of Total relationships, and these results confirm the importance of lean leadership behaviors in helping organizations in the field of application achieve a strategic balance, in terms of how to deal with the capabilities and resources available in their internal environment and control them, or in terms of monitoring opportunities and challenges and taking the necessary measures to deal with them to maintain their position in the sector You're working on, either This was through behavioral humility and how to deal with the parties related to its operations, or calmness behavior that dealt with critical and exceptional situations, or wisdom behavior when making decisions affecting its future. As for objective behavior, it exercises its role in achieving justice when assessing the human resources working within it, and plays The behavior of trust plays its role when engaging in various projects, and finally, the behavior of patience has its own importance through deliberation and not rushing to exploit external opportunities. What confirms these results is the value of the correlation relationship between lean driving aggregate and total strategic equilibrium variable of $(0.911 * *)$, which is a strong and positive correlation with significant significance at level (0.1). Therefore, these results can be based on accepting the first main hypothesis of the research, which includes: "Adopting lean leadership behaviors plays a significant role statistically in the strategic balance of the researched organizations."

Fourth: Analyzing and interpreting the results of the influence relationships between lean leadership and strategic balance

Table (6) shows the results of analyzing the impact relationships of lean leadership (the explanatory variable) through its six dimensions, in the strategic balance (response variable) using the simple regression coefficient, and the researcher relied on the value of (f) calculated in testing the hypotheses of impact, and in the light of which the relationship was formulated The function between them, as in the following equation:

$\mathbf{Y}=\mathbf{a}+\mathbf{B X}$

Table (6) the results of the impact relationships of lean leadership and its dimensions in the strategic balance

\begin{tabular}{|c|c|c|c|c|c|c|}
\hline & B & $\mathbf{a}$ & $\mathbf{R}^{2}$ & $\mathbf{F}$ & Moral & $\begin{array}{l}\text { Relative } \\
\text { importance }\end{array}$ \\
\hline $\begin{array}{l}\text { Confidence } \\
\text { behavior }\end{array}$ & 0.71 & 1.19 & $\% 61$ & 266.72 & 0.001 & $\% 100$ \\
\hline $\begin{array}{l}\text { Wisdom } \\
\text { behavior }\end{array}$ & 0.74 & 1.03 & $\% 63$ & 352.40 & 0.001 & $\% 100$ \\
\hline $\begin{array}{l}\text { Calm } \\
\text { behavioral }\end{array}$ & 0.70 & 1.19 & $\% 72$ & 454.55 & 0.001 & $\% 100$ \\
\hline $\begin{array}{l}\text { Behavioral } \\
\text { patience }\end{array}$ & 0.69 & 1.26 & $\% 64$ & 413.87 & 0.001 & $\% 100$ \\
\hline $\begin{array}{l}\text { Humility } \\
\text { behavior }\end{array}$ & 0.70 & 1.13 & $\% 61$ & 339.68 & 0.001 & $\% 100$ \\
\hline $\begin{array}{l}\text { Objective } \\
\text { behavior }\end{array}$ & 0.71 & 1.18 & $\% 65$ & 369.08 & 0.001 & $\% 100$ \\
\hline
\end{tabular}




\begin{tabular}{|c|c|c|c|c|c|c|}
\hline $\begin{array}{l}\text { Aggregate lean } \\
\text { leadership } \\
\text { behavior } \\
\text { variable }\end{array}$ & 0.93 & 0.27 & $\% 83$ & 967.88 & 0.001 & $\% 100$ \\
\hline
\end{tabular}

Source: Prepared by the researchers, 2020.

From Table (6) to determine the effect of the lean leadership variable on the strategic balance, we find that the calculated value of (f) reached its peak (967.88) which is greater than its tabular value, at a significant level (0.001) and with confidence limits (999\%), and these results confirm There is a significant effect of lean leadership on the strategic balance, and the current regression model is good to describe the relationship of influence between them from a statistical point of view, as the value of the constant $(0.27 \mathrm{a}=)$ This means that there is a strategic balance of $(0.27)$ even if the lean leadership is equal to zero, and the value of $(0.93 \mathrm{~B}=)$, i.e., changing lean leadership by one unit will result in a change in equilibrium a Strategic amounted to (0.93), while the value of (R2) reached (83\%), meaning that $(83 \%)$ of the variance in the strategic balance $(\mathrm{Y})$ is explained by the graceful leadership (X) that entered the model, and that (17) \%) Only is an explanatory variation of other factors not included in the regression model. The number of regression models with a significant effect, as shown in Table (49), reached (7) models out of (7), meaning that their percentage $(100 \%)$ of the total moral influence relationships from a statistical point of view, and since the total of the lean leadership variable achieved an effect Morally in the total strategic equilibrium variable as well. Hence, it is possible to benefit from the previous results in presenting the basis upon which the researcher relied on accepting the second main hypothesis of the research, which says: "Lean leadership behaviors contribute statistically from a statistical point of view to the strategic balance of the researched organizations" on the aggregate and individual levels, and the regression equation can be formulated between (X) And (Y) are as follows:

Strategic balance $=0.27+0.93 *($ Lean leadership $)$

THE FOURTH TOPIC: CONCLUSIONS AND RECOMMENDATIONS

The researchers try to present the most prominent conclusions that they reached in the framework of the results of the analysis, and then present some recommendations that would address deficiencies within the researched organizations, and as far as the matter relates to the variables discussed and as in the following two paragraphs:

\section{First: the conclusions}

1. The results of the analysis confirmed that the leaders in the researched organizations enjoy a set of graceful behaviors, which enable them to implement the activities and tasks assigned to them in a manner that is consistent with global standards and indicators, and in coordination with all parties that relationship, to ensure that everyone's interests are served without any conflict or conflict between them To achieve their goals and the goals of their organization.

2. Leadership in the researched organizations has the behavior of humility when dealing with its human resources, and this was represented by taking their opinions and proposals into consideration when implementing their operations and entering into various projects, as well as by empowering them with powers and enabling them to assume responsibility on their shoulders, and not restricting them to the leadership only .

3. The leaderships in the researched organizations adopt a set of clear criteria and indicators when dealing with the achievements and evaluation of the performance of their human resources, and provide them with feedback in order to solidify their contribution to achieving the goals of their organizations to maintain their career positions, and here the importance of objective behavioral among the higher leaderships emerges.

4. There is a clear interest among the researched organizations in achieving a strategic balance through monitoring developments in their external environment and monitoring them first-hand, in order to put in place procedures and instructions that the variables of their internal environment are going to adapt to. 
5. The research organizations face the various fields related to government regulations and laws, cultural trends and economic fields related to the availability of material and human resources, which can deal with them as fields of opportunities, and employ them to consolidate their position in the sector in which they operate and then ensure their survival and continuity in work.

6. The administration in the researched organizations possesses the integrated vision to draw policies and mechanisms that enable them to invest the available capabilities in the best possible way, in addition to seeking to modernize their infrastructure in a manner that is compatible with contemporary developments, in particular through attention to updating their databases and information.

7. The lean leadership plays an important role in monitoring the challenges facing the researched organizations more compared to monitoring opportunities, and then enhances the commitment of its human resources when dealing with these challenges, through controlling the capabilities and resources available to them and employing their behaviors in implementing control programs, to achieve compatibility Among them to take decisions that invest the opportunities available to them and reduce the negative effects of the challenges, and may be due to the volatile nature of the Iraqi environment.

8. The greatest role that humility behavior plays in achieving the strategic balance of the researched organizations, through the commitment and control of their human resources, highlights the fact that it encourages them to monitor information on the developments taking place in their internal and external environment, and present them to the leadership system, without fear or hesitation because they are dealing With them modestly and in a spirit of friendship and familiarity.

9. The lean leadership exerts a moral influence in achieving the strategic balance through supervision and coordination between the internal resources of the researched organizations, and then preserving the capabilities and enhancing the commitment of their human resources, in a manner that enables them to take advantage of the available opportunities and avoid challenges in the external environment.

10. Quiet behavior exerts a significant moral effect on achieving the strategic balance of the researched organizations by acting wisely and carefully during the critical and exceptional situations that can be exposed to them within the framework of its internal and external home.

\section{Second: Recommendations}

1. The researcher recommends the research organizations to familiarize themselves with the experiences previously applied in the advanced countries in the field of lean leadership, and try to apply their results in a manner that enhances the degree of flexibility and agility enjoyed by the leaders working with them, to enhance the flexible directions that they adopt in carrying out their various operations, from During the establishment of cooperative relations with it.

2. The researcher proposes to the researched organizations the formation of committees from all organizational levels, which will determine the foundations adopted in taking opinions and proposals for their human resources, and the mechanism for distributing responsibilities within them and delegating powers in order to create a climate of humility in a clear degree.

3. The researcher believes that the researched organizations should prepare documentation of the nature of the activities and tasks assigned to their human resources while specifying the appropriate times to accomplish them, to ensure calm in the work and not rush or negligence in its completion, which can be reflected in the quality of its services and then its reputation in society.

4. The necessity for the research organizations to amend their financial and non-financial plans and policies in a manner that enhances balance with successive developments between the internal and external environments, by resorting to consulting experts with expertise in this field to take the necessary decisions to maintain their strategic balance.

5. The necessity of working to establish links and channels of communication with other organizations, to identify all that is new in the field

\section{INTERNATIONAL JOURNAL OF RESEARCH IN SOCIAL SCIENCES AND HUMANITIES}


of work of the researched organizations, which represents opportunities that can be used to enhance its position within the sector that operates within its borders, in a way that ensures progress and nonregression compared to competition to her .

6. The researcher recommends the importance of spreading a culture within the researched organizations that enhances the conviction of the human resources working for them, of the necessity of preserving the capabilities and using them in carrying out the necessary tasks, while preserving them and not wasting them, to ensure their preservation and not being affected by their shortage in austerity or other exceptional situations.

7. The researcher believes that the researched organizations should establish a section that will monitor the external challenges and opportunities, and provide detailed information about them to the leaders in them, to ensure the preservation of the grace that they enjoy when managing and moving their internal capabilities and resources in a manner that is compatible with those external developments, to maintain their balance .

8. The researcher believes that the researched organizations should prepare timetables about the most important investment fields that they wish to make and work according to, to ensure that the decisions that adversely affect their position towards the opportunities and external challenges, or manage their available capabilities internally are not managed.

9. The researcher suggests that the researched organizations rely on the style of the work teams to ensure integration and merging between the newly appointed leadership cadres with the old leadership cadres to enhance learning processes and benefit between them, and then enhance their ability to contribute to achieving the strategic balance of their organizations.

10. The researcher stresses the importance of encouraging the researched organizations their leaders to take decisions and participate in them by giving them sufficient powers to do so and in coordination with the higher departments, to ensure strengthening their wisdom behaviors and then upgrading their levels of influence on the strategic balance of their organizations.

\section{RESOURCE :}

1. Alshebli, Abdulla (2016) Improving Capabilities and Strategic Fit in Governmental Agencies : The Case of Abu Dhabi Government Infrastructure Sector, A thesis submitted in partial fulfillment of the requirements of the University of Wolver Hampton for the degree of Doctor of Philosophy.

2. Amer, Hend \& Shaw, Corrinne (2015) Lean Leadership Paradoxes: A Systematic Literature Review, The International Journal of Human Resource Management, Vol 23, No 17 : pp272-283.

3. Andersson, Christine \& Andersson, Hanna (2014) Lean leadership - The Toyota Way in Agricultural Firms, Master's thesis of Agricultural Programmer Economics \& Management, Swedish University of Agricultural Sciences, Department of Work Science, Business Economics and Environmental Psychology.

4. Barth, Henrik (2003) Strategy Fit among Competitive Strategy,Administrative Mechanisms, and Performance: A Comparative Study of Small Firms in Mature and New Industries, Journal of Small Business Management, Vol 41, No 2 : pp 133-147.

5. Begam, M. Shabeena \& Swamynathan, R. \& Sekkizhar, J. (2013) Current Trends on Lean Management - A review, International Journal of Lean Thinking, Vol 4, No 2 : pp 15-21.

6. Destri, Arabella Li \& Picone, Pasquale Massimo \& Minà, Anna (2012) From "Strategic Fit" to Synergy Evaluation in M\&A Deals, Caspian Journal of Applied Sciences Research, Vol 1, No 12 : pp 25-38.

7. Emiliani, ML (1998) Lean Behaviors, journal of Management Decisions, Vol 36 : pp 615-631. 
8. Fernando, Mario \& Klaus, Lauren (2016) Enacting spiritual leadership in business through ego-transcendence, Leadership \& Organization Development Journal, Vol 37, No 1 : pp.71-92.

9. Halling, Bengt \& Renstrom, Jonas (2015) Lean leadership: a matter of dualism , International Journal of Human Resources Development and Management, Vol 14, No 4 : pp 1503 : 1510.

10. Iman, Nofie \& Hartono, Jogiyanto (2007) Strategic alignment impacts on organizational performance in Indonesian banking industry, Gadjah Mada International Journal of Business, Vol 9, No 2 : pp 253-272.

11. Jhajharia, Parul \& Kaur, Ritika (2015) Achieving Strategic-Fit Between Business And Human Resource Strategies, International Journal of Humanities and Social Science Invention, Vol 4, No 1 : PP 53-61.

12. Kearns, Grover S. \& Sabherwal, Rajiv (2007) Strategic Alignment Between Business and Information Technology: A Knowledge-Based View of Behaviors, Outcome, and Consequences, Journal of Management Information Systems, Vol 23, No 3 : pp 129-162.

13. Ljungblom, Mia (2012) A Comparative Study Between Developmental Leadership and Lean Leadership Similarities and Differences, Management and Production Engineering Review, Vol 3, No 4 : pp 54-68.

14. Lopez-Fresno, Palmira (2012) Contribution of Lean Management to Excellence, Nang Yan Business Journal, Vol 1, No1 : pp90-98.

15. Majukwa, Donnemore (2016) Operations management impact on achieving strategic fit: A case from the retail sector in Zimbabwe, journal of Cogent Business \& Management, Vol 6 : pp 1-16.

16. Marksbeffy . p \& Hughes. s (2011) the role of the executive in leam : A qualitative thesis based on the Toyota production system, international journal of lean thinking, Vol 2, No 2 : pp 2-19.

17. Marques, Joan (2013) Understanding the Strength of Gentleness: Soft-Skilled Leadership on the Rise, journal of Business Ethics, Vol 161 : pp 163-171.

18. Mohabir, S. (2008) The association between ambidexterity, strategic orientation and business performance in the financial services (banking) sector, A research project submitted to the Gordon Institute of Business Science, University of Pretoria, in partial fulfilment of the requirements for the degree of Master of Business Administration. University of Pretoria.

19. Moses, Okebaram Sunday \& Ekwutosi, Onuoha Charity (2018) Implication of Strategic Fit and Sustainability on Organizational Effectiveness, International Academic Research Conference in Vienna, Vol 21, No 4 : pp194-213.

20. Mulders, Karin (2016) Embracing Lean leadership: an empirical study on the interaction between Lean leadership principles and a successful Lean implementation at the team-level of analysis, Master's thesis in Organization Studies, Tilburg University.

21. Nicholas, John (2010) Lean Production for Competitive Advantage: A Comprehensive Guide to Lean Methodologies and Management Practices, An electronic version is available on the website for Taylor and Francis Group, productivity press.

22. Nkhwangwa, Lordwell C.T. (2014) Achieving strategic fit /integration between business strategies and human resource management (HRM) strategics in the banking sector : an assessment banks in malawi, International Journal of Social Sciences and Management, Vol 1, No 4: pp 143-159.

23. Noordin, Fauziah \& Omar, Safiah \& Sehan, Syakirarohan \& Idrus, Shukriah (2010) $\underline{\text { Organizational Climate And Its }}$ Influence On Organizational Commitment, International Business \& Economics Research Journal, Vol 9, No 2 : pp110.

24. Osma, Beatriz García \& Pope, Peter F. (2011) Strategic Balance Sheet Adjustments under First-Time IFRS Adoption and the Consequences for Earnings Quality, Electronic copy available at: www.ssrn.com.

25. Puvanasvaran, Perumal \& Megat, Hamdan \& Hong, Tang Sai \& Razali, Muhamad Mohd \& Magid, Hamouda Abdel (2016) Lean process management implementation through enhanced problem solving capabilities, journal of industrial engineering and management, Vol 3, No $3: 477-493$. 
26. Rahman, Habibur \& Rahman, Azizur (2019) Strategic fit: model development and fitness analysis of a manufacturing unit, Production \& Manufacturing research, Vol 7, No 1 : pp 44-66.

27. Rotemberg, Julio J. \& Saloner, Garth (2000) Visionaries, managers, and strategic direction, Journal of Economics, Vol 31, No 4 : pp 693-716.

28. Rudelius, Krein .H (2007) Marketing the Core, 2 Edition, New Jersey.

29. Schipper, Timothy \& Swets, Mark (2010) Innovation Lean Development How to Create, Implement \& Maintain A Learning Culture Using Fast Learning Cycles, An electronic version is available on the website for Taylor \& Francis Group, New York, USA.

30. Schwagerman, William C. \& Ulmer, Jeffrey M (2013) The A3 Lean Management and Leadership Thought Process, Journal of Technology, Management and Applied Engineering, Vol 29, No 4 : pp 1-10.

31. Shatrevich, Vladimir \& Gaile-Sarkane, Elina (2015) A Strategic Fit Relation Model as a Tool for Organization Development, Academy of Management Journal, Vol 34, No 3 : pp1-7.

32. Teich, Sorin T. \& Faddoul, Fady (2013) Lean Management-The Journey from Toyota to Healthcare, Rambam Maimonides Medical Journal, Vol 4, No 2 : pp1-9.

33. Thuresson, Jennie \& Östman, Maria (2017) The Practice of Value Stream Management and Lean Leadership in a Matrix Organization A Case Study in the Aerospace Industry, Master's Thesis in the Master's Programme Quality and Operations Management, Chalmers university of technology .

34. Van, T. Diana (2011) Ensuring dynamic strategic fit of firms that compete globally in alliances and networks: proposing the Global SNA "Strategic Network Analysis" framework, journal of rap-Rio de Janeiro, Vol 45, No 1 : pp67-105.

35. Wheelen, Thomas .L\& Hunger, David .J (2010) Concepts in strategic management and Business policy Achieving Sustainability, 12 Edition, Pearson, New Jersey .

36. Xu, S \& Cavusgil, S. T \& White, J (2006) The impact of strategic fit among strategy, structure, and processes on multinational corporation performance: A multimethod assessment ,Journal of International Marketing, Vol 14, No $2:$ pp 1-31.

37. Yukl, Gary \& Mahsud, Rubina (2010) Why fiexible and adaptive leadership is essential, Consulting Psychology Journal: Practice and Research, Vol 62, No 2 : pp 81-93.

38. Zulkiffli, Noorul . A \& Latiffi, Aryani . A (2019) Review on Project Manager's Leadership Skills in the PreConstruction Phase of Sustainable Construction Projects, Matec Web of Conferences, Vol 266 :pp 1-7. 